\title{
Effects of sublingual-specific immunotherapy on pulmonary function and exhaled nitric oxide levels in asthmatic children with and without allergic rhinitis
}

\author{
Tao Ai, Li Wang, Ronghua Luo, Yinghong Fan, Huiling Liao, Wanmin Xia, Lei Zhang, Yaping Duan \\ Department of Pediatric Respiratory Medicine, Chengdu Women's and Children's Central Hospital, School of Medicine, University of Electronic \\ Science and Technology of China, Chengdu, China \\ Contributions: (I) Conception and design: T Ai, L Wang; (II) Administrative support: R Luo; (III) Provision of study materials or patients: Y Fan; \\ (IV) Collection and assembly of data: H Liao, W Xia, L Zhang, Y Duan; (V) Data analysis and interpretation: L Wang; (VI) Manuscript writing: All \\ authors; (VII) Final approval of manuscript: All authors. \\ Correspondence to: Li Wang. Chengdu Women's and Children's Central Hospital, School of Medicine, University of Electronic Science and \\ Technology of China, Chengdu, China. Email: 625664758@qq.com.
}

Background: Allergic asthma and allergic rhinitis are common chronic respiratory diseases in children. The prevalence rate of disease is increasing year by year. And avoid allergens, drug treatments and special immunotherapy (SIT) is the fundamental treatment for respiratory allergies diseases. But there are few comprehensive studies on the control level of asthma, improvement of lung function, and changes of exhaled nitric oxide (FeNO) after SLIT treatment in children with allergic asthma and rhinitis.

Methods: In all, 71 child asthma patients who received sublingual-specific immune therapy for 1 year or more were divided into an asthmatic rhinitis group (31 cases) and an asthma-alone group (40 cases). The two groups of patients were compared before and after treatment in terms of rhinitis symptom scores, daytime and nighttime asthma symptom scores, visual analog scale (VAS) score, drug score, pulmonary function, and exhaled nitric oxide level (FeNO).

Results: After treatment, daytime symptom scores, VAS scores, drug scores, and FeNO levels of the asthma-alone group were all lower than before treatment, and the lung function was significantly improved $(\mathrm{P}<0.05)$, while the difference in night symptom scores before and after treatment was not statistically significant $(\mathrm{P}>0.05)$. The lung function and FeNO level of children in the asthmatic rhinitis group were lower after treatment than before treatment, with statistically significant differences $(\mathrm{P}<0.05)$. The scores of rhinitis and VAS in the asthmatic rhinitis group were higher than those in the asthma-alone group, and the differences were statistically significant. There was no significant difference in other scores between the two groups. There was no significant difference in lung function and FeNO level between the two groups.

Conclusions: SLIT for children with or without allergic asthma or with or without rhinitis has a significant effect, but its effect on children with asthma combined with rhinitis is not superior to that of children with asthma alone.

Keywords: Sublingual-specific immunotherapy (SLIT); asthma; allergic rhinitis (AR); children

Submitted Sep 11, 2020. Accepted for publication Oct 20, 2020.

doi: $10.21037 / \mathrm{tp}-20-322$

View this article at: http://dx.doi.org/10.21037/tp-20-322 


\section{Introduction}

Allergic respiratory diseases in children mainly include allergic rhinitis (AR) and asthma, which are noninfectious inflammatory diseases mediated by silicon-germanium ( $\mathrm{IgE}$ ) in the respiratory mucosa after children with allergic constitutions have been exposed to allergens (1). In recent years, the incidence of respiratory allergic diseases in children has been increasing. The third epidemiological survey of childhood asthma in 2013 showed that the 2-year prevalence rate of asthma in urban children aged $0-14$ years was $2.32 \%$ on average, and the cumulative prevalence rate was $3.02 \%$ on average. In all, $50.1 \%$ of these children were also accompanied by AR (2). Compared with the results of the national epidemiological survey of childhood asthma in 2000 , the current incidence of asthma increased by $50.6 \%$ and the cumulative prevalence increased by $53.3 \%$. In China, the survey data of AR in different regions fluctuates greatly. Zhao et al. (3) conducted an epidemiological survey on children's AR in Beijing, Chongqing, and Guangzhou by using a multi-order sampling method, and found that the prevalence rate was $14.46 \%, 20.42 \%$, and $7.83 \%$, respectively, with the prevalence level gradually increasing.

Allergen immunotherapy (AIT) has been recommended to treat AR and asthma. AIT mainly includes sublingualspecific immunotherapy (SLIT) and subcutaneousspecific immunotherapy (SCIT), both of which can alleviate patients' respiratory symptoms, reduce the use of appropriate drugs, and improve patients' quality of life (4). Both of the above approaches have been proved effective in treating children with respiratory irritability. The results of meta-analysis showed that both SCIT and SLIT were safe and effective in treating dust mite allergic rhinitis. However, no unanimous conclusion has been reached on the merits of the two methods in treating children with asthma (5), at present, only a few literatures have been reported. Miao et al. (6) found that different immunotherapy approaches had time differences in the intrinsic immunological response of asthmatic children, among which SCIT immunotherapy children showed earlier immune response. However, because of the limited delivery method of SCIT and the high requirement of patient compliance, its clinical application was greatly limited, while SLIT was more easily accepted by patients and their families. The World Allergy Organization (WAO) indicated that although the clinical efficacy of SLIT is limited by the dose, course, and patient selection, the effectiveness of SLIT in adult rhinitis and conjunctivitis and in asthma and rhinitis in children is worth promoting (7). SLIT in children with allergic asthma or AR has been studied in China $(8,9)$, but there are few comprehensive studies on the improvement of lung function, and changes of exhaled nitric oxide ( $\mathrm{FeNO}$ ) after SLIT treatment in children with allergic asthma and rhinitis. Therefore, dust mite drops were used in this study to treat children with asthma and rhinitis, and the clinical efficacy, pulmonary function level, and the changes of FeNO indexes were observed. We present the following article in accordance with the STROBE reporting checklist (available at http://dx.doi.org/10.21037/tp-20-322).

\section{Methods}

\section{Research subjects}

SLIT treatment of asthma with rhinitis was randomly selected from February 2016 to February 2018 in 48 cases of children admitted to our hospital with asthma and rhinitis. After a year of follow-up, 8 cases were lost to follow-up. For acute asthma attacks [less than $70 \%$ of the expected forced expiratory volume in one second $\left.\left(\mathrm{FEV}_{1}\right)\right]$, termination of desensitization therapy occurred in 5 cases, and 4 cases were out on their own research. Ultimately, 31 cases completed the follow-up.

SLIT treatment of asthma without allergic rhinitis in our hospital in the same time was selected as the asthma group. Fifty-six children were placed into the group. After 1 year of follow-up, 5 cases were lost to follow-up for acute asthma attacks in the process of follow-up (less than $70 \%$ of the expected $\mathrm{FEV}_{1}$ ), termination of desensitization therapy occurred in 5 cases, and 6 cases withdrew from the study by themselves. Finally 40 cases completed the follow-up.

The inclusion criteria: (I) the diagnosis and treatment of patients were based on The Guidelines for Diagnosis and Treatment of Allergic Rhinitis in Children (2010, Chongqing) and the Guidelines for Prevention and Treatment of Bronchial Asthma in Children (2016). Accordingly, the inclusion criteria were the following: (II) children with asthma in remission stage; (III) tested for allergen skin puncturing before treatment, with the results showing dust mites and/ or household dust mite were positive; meanwhile, the exclusion criteria were the following: (I) acute asthma attack with $\mathrm{FEV}_{1}$ less than $70 \%$ of the expected value; (II) loss to follow-up or withdrawal from the study due to various reasons; (III) occurrence of a severe allergic reaction. 
Table 1 Allergic rhinitis symptom rating scale (12)

\begin{tabular}{lllll}
\hline Grade & Sneeze $^{\mathrm{A}}$ (number) & Runny nose $^{\mathrm{B}}$ (number) & Rhinobyon & Rhinocnesmus \\
\hline 1 & $3-5$ & $\leq 5$ & Consciously inhaling & Discontinuous \\
2 & $6-10$ & $6-9$ & Interactivity & Formication, endurable \\
3 & $\geq 11$ & $\geq 10$ & Breathing through mouth almost all day & Formication, unendurable \\
\hline
\end{tabular}

${ }^{A}$, the number of a consecutive sneezes; ${ }^{B}$, the number of times you blow your nose.

Table 2 Evaluation of daytime and nighttime symptoms of asthma (13)

\begin{tabular}{|c|c|c|}
\hline Grade & $\begin{array}{l}\text { Daytime symptom score for } \\
\text { asthma }\end{array}$ & $\begin{array}{l}\text { Nighttime symptom } \\
\text { score for asthma }\end{array}$ \\
\hline 0 & Asymptomatic & Asymptomatic \\
\hline 1 & $\begin{array}{l}\text { Few symptoms and very short } \\
\text { duration }\end{array}$ & Wake up once or early \\
\hline 2 & $\geq 2$ times very short symptoms & Wake up 2 times \\
\hline 3 & $\begin{array}{l}\text { Symptoms are mild for many } \\
\text { parts of the day, but have little } \\
\text { impact on life and work }\end{array}$ & Wake up many times \\
\hline 4 & $\begin{array}{l}\text { Symptoms are severe at more } \\
\text { times of the day, affecting life } \\
\text { and work }\end{array}$ & $\begin{array}{l}\text { Unable to sleep at } \\
\text { night }\end{array}$ \\
\hline 5 & \multicolumn{2}{|c|}{$\begin{array}{l}\text { Symptoms are so severe that the subject is unable to } \\
\text { work and live a normal life }\end{array}$} \\
\hline
\end{tabular}

\section{Research methods}

In this study, sublingual desensitization treatment was performed with sublingual dust mite drops (national drug approval No. S20060012) produced by Zhejiang Wolwo Biotechnology Co., Ltd (Zhejiang, China), which were divided into 1-4 bottles, with corresponding total protein concentrations of $1,10,100$, and $333 \mu \mathrm{g} / \mathrm{mL}$. The drug was placed under the tongue for 1-3 minutes before swallowing. The treatment process includes the increment phase and the maintenance phase. During the increment phase, bottles 1 , 2 , and 3 were used in order for 1 week each, and 1, 2, 3, 4, 6, 8 , and 10 drops of duster were administered from day 1 to day 7 of each week. Dust mite drop no. 4 was administered at 3 drops/time/day, until the end of the treatment period. SLIT therapy was adopted, and other corresponding drugs were used to treat asthma and rhinitis according to the clinical symptoms.

\section{Lung function tests}

Lung function was determined by the Master Screen lung function instrument (Jaeger GmbH, Cologne, Germany). The parameters include forced vital capacity (FVC), forced expiratory volume in one second $\left(\mathrm{FEV}_{1}\right), \mathrm{FEV}_{1} /$ FVC, maximum forced peak flow expiratory (PEF), forced expiratory flow $\left(\mathrm{FEF}_{25}, \mathrm{FEF}_{50}, \mathrm{FEF}_{75}\right)$, and maximum midexpiratory flow (MMEF) (10).

\section{Determination of exhaled nitric oxide}

AN exhaled nitric oxide (FeNO) tester (NIOX VERO, Sollentuna, Sweden) was used to measure the exhaled nitric oxide index of children. FeNO levels were measured in accordance with the standardized FeNO assay guidelines recommended by the American Thoracic Society/European Respiratory Society (ATS/ESR) (11).

All procedures performed in this study involving human participants were in accordance with the Declaration of Helsinki (as revised in 2013). The study was approved by ethics board of Chengdu Women and Children Center Hospital and informed consent was taken from all the patients.

\section{Evaluation index}

\section{Symptom scores}

The severity of the main symptoms of rhinitis was assessed by the "four-point method" (Table 1) (12). The symptom score of asthma included daytime symptom score, nighttime symptom score, and visual analog scale (VAS) score, which depended on the severity of the symptoms and their impact on life (Table 2) (13).

\section{Drug scoring}

A quantitative index of the application of symptomatic 
Table 3 Symptomatic drug rating scale (14)

\begin{tabular}{ll}
\hline Grade & Symptomatic treatment drugs \\
\hline 1 & Oral and/or topical antihistamines \\
& Antileukotrienes \\
& Bronchodilators \\
2 & Nasal corticosteroids/inhaled corticosteroids \\
3 & Oral glucocorticoids \\
& $\begin{array}{l}\text { Combination therapy (hormone and beta2-receptor } \\
\text { agonist) }\end{array}$ \\
\hline
\end{tabular}

Table 4 Comparison of scores before and after treatment in asthma-alone group

\begin{tabular}{lcccc}
\hline Evaluation index & Prior treatment & Post-treatment & $Z$ & $P$ \\
\hline $\begin{array}{l}\text { Daytime } \\
\text { symptom score }\end{array}$ & $0.0(0.0,1.8)$ & $0.0(0.0,0.0)$ & 3.451 & 0.001 \\
$\begin{array}{l}\text { Nighttime } \\
\text { symptom score }\end{array}$ & $3.0(1.3,4.0)$ & $4.0(0.3,4.0)$ & 0.198 & 0.843 \\
VAS score & $5.0(3.0,6.0)$ & $0.0(0.0,2.0)$ & $5.187<0.001$ \\
Drug score & $3.0(3.0,4.0)$ & $0.0(0.0,2.0)$ & $5.343<0.001$ \\
\hline
\end{tabular}

The data were shown as after treatment, the scores of daytime symptoms, VAS scores and drug scores in the asthma-alone group were lower than those before treatment, and the differences were statistically significant. There was no statistically significant difference in the scores of night symptoms before and after treatment.

Table 5 Comparison of scores before and after treatment in the asthmatic rhinitis group

\begin{tabular}{lcccc}
\hline Evaluation index & Prior treatment Post-treatment & $Z$ & $P$ \\
\hline Rhinitis score & $3.0(2.0,4.0)$ & $1.0(1.0,1.0)$ & $4.760<0.001$ \\
$\begin{array}{l}\text { Daytime } \\
\text { symptom score }\end{array}$ & $1.0(0.0,1.0)$ & $0.0(0.0,0.0)$ & $3.499<0.001$ \\
Nighttime & $0.0(0.0,0.0)$ & $0.0(0.0,0.0)$ & 2.530 & 0.011 \\
symptom score & & & & \\
VAS score & $4.0(2.0,5.0)$ & $2.0(1.0,3.0)$ & $4.617<0.001$ \\
Drug score & $4.0(4.0,5.0)$ & $0.0(0.0,2.0)$ & $4.842<0.001$ \\
\hline
\end{tabular}

The data were shown as the scores of rhinitis, daytime symptom scores, nighttime symptom scores, VAS scores and drug scores of asthmatic rhinitis group were all lower after treatment than before treatment, and the differences were statistically significant. drugs was used to record the use of symptomatic drugs in the children, so as to evaluate the clinical efficacy of immunotherapy. Our study adopted the "three-step" scoring method (Table 3) (14).

\section{Statistical analysis}

SPSS 17.0 software (IBM, Armonk, NY, USA) was used for statistical analysis of the data. If the quantitative data were normally distributed, the mean \pm standard deviation (SD) was used for description, and two independents sample $t$-test (Student's $t$-test) was used for comparison between the groups. The quantitative data are described by median, upper, and lower quartile (M, P25-P75) for non-normal distribution, and the rank-sum test of the two independent samples was used for intergroup comparison (Mann-Whitney $\mathrm{U}$ test). Qualitative data are described by percentage, and comparisons between groups were performed by chi-square test. The cut-off value of $\mathrm{P}$ was 0.05 .

\section{Results}

There were 31 patients in the asthmatic rhinitis group, including 24 males (77.4\%) and 7 females (22.6\%), and 40 patients in the asthma-alone group, including 23 (57.5\%) males and $17(42.5 \%)$ females. There was no significant difference in gender composition between the two groups $\left(\chi^{2}=3.097, \mathrm{P}=0.078\right)$. The mean age of the asthmatic rhinitis group was $6.6 \pm 2.5$ years old, and that of the asthmatic group was 7.6 \pm 3.2 years old. There was no significant difference in age between the two groups $\left(\chi^{2}=1.567, \mathrm{P}=0.122\right)$.

After treatment, the scores of daytime symptoms, VAS scores, and drug scores in the asthma group were lower than those before treatment, and the differences were statistically significant. There was no statistically significant difference in the scores of night symptoms before and after treatment (Table 4). The scores of rhinitis, daytime symptom scores, nighttime symptom scores, VAS scores, and drug scores of patients with asthma combined with rhinitis were all significantly lower after treatment than before treatment $(\mathrm{P}<0.05)$ (Table 5).

For both the asthma-alone group alone and the asthmatic rhinitis group, the pulmonary function index of the children after treatment was significantly improved compared with that before treatment, while the FeNO level after treatment was significantly decreased compared with that before treatment $(\mathrm{P}<0.05)($ Tables 6,7).

The VAS score of patients with asthma combined with 
Table 6 Comparison of lung function indexes and FeNO before and after treatment in the asthma-alone group

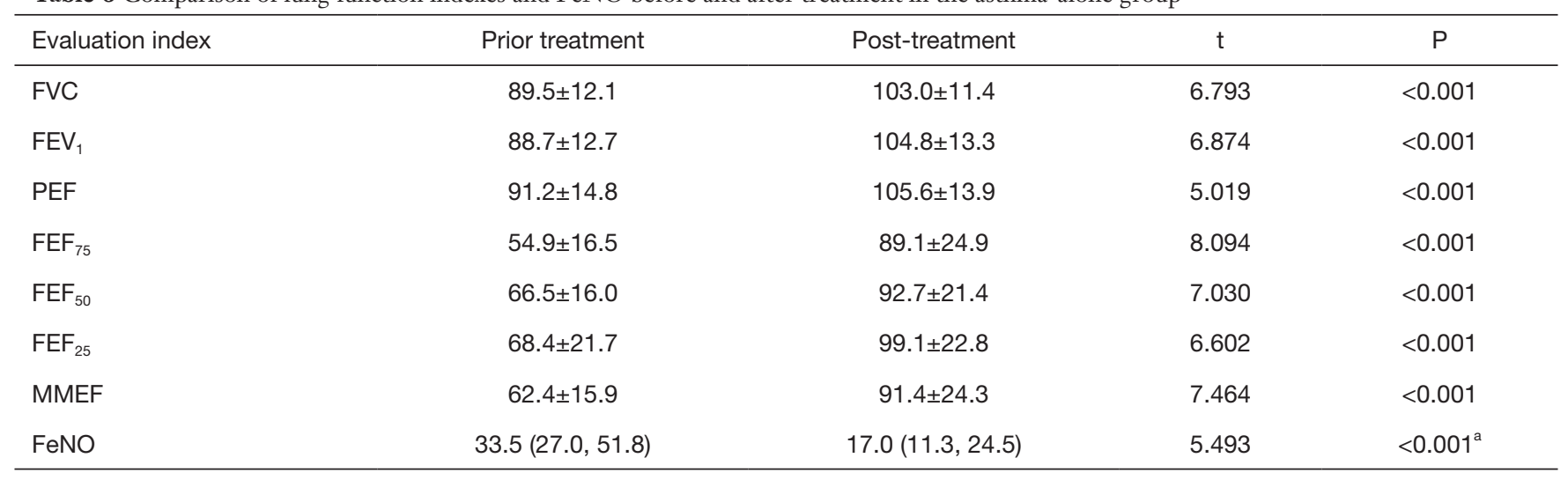

${ }^{a}$, rank-sum test of two independent samples (Mann-Whitney $U$ Test). The data were shown as the lung function indexes of the children after treatment were significantly improved compared with that before treatment, while FeNO level after treatment was significantly decreased compared with that before treatment, with statistically significant differences in the asthma-alone group.

Table 7 Comparison of lung function indexes and FeNO before and after treatment in the asthmatic rhinitis group

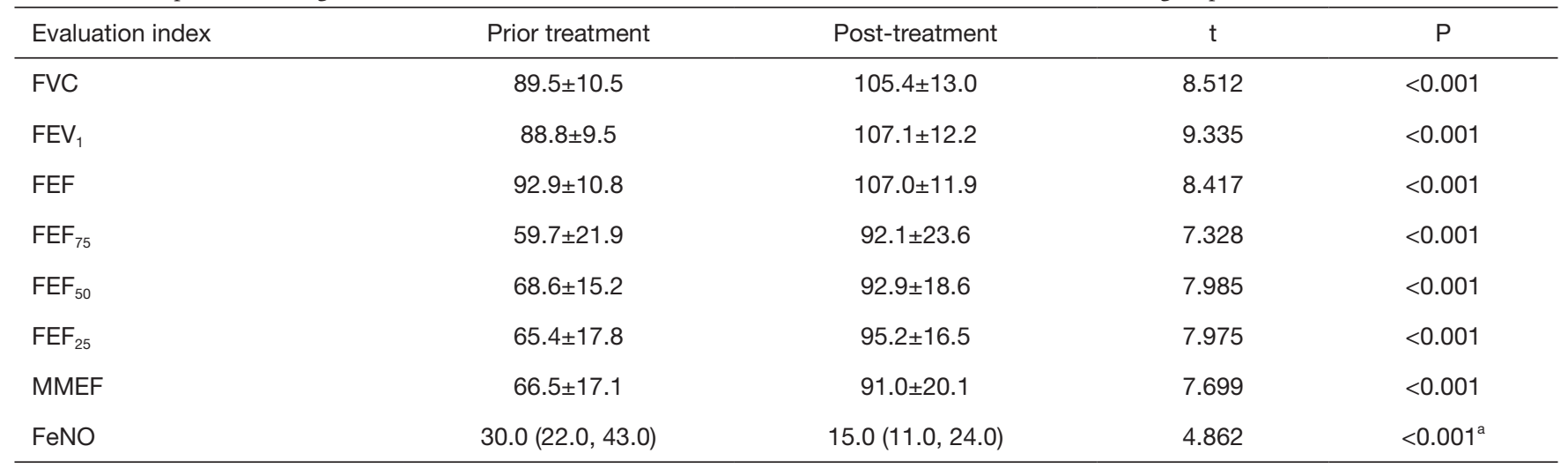

${ }^{a}$, rank-sum test of two independent samples (Mann-Whitney $U$ Test). The data were shown as the lung function indexes of the children after treatment were significantly improved compared with that before treatment, while FeNO level after treatment was significantly decreased compared with that before treatment, with statistically significant differences in the asthmatic rhinitis group.

rhinitis was higher than that of patients with asthma alone, and the difference was statistically significant. There was no significant difference in the other scores between the two groups (Table 8). There was no significant difference in lung function and FeNO between the two groups (Table 9).

\section{Discussion}

The natural process of allergic diseases means that their occurrence and development follow certain patterns (15); that is, the onset of allergic diseases begins in infancy and generally manifests as a food allergy or skin eczema. Most of these symptoms resolve automatically by the age of 3 , but children in this group have a significantly increased risk of developing respiratory allergic diseases in their teens, especially asthma with/without AR. Allergic asthma and variant rhinitis are the most common respiratory allergic diseases that seriously affect the quality of life of children. Allergens are common factors that induce allergic asthma and variant rhinitis, while dust mites are the main allergens that cause asthma (16).

Children's respiratory allergic diseases are chronic noncommunicable diseases, and the management of diseases refers to the "four-in-one" treatment principle, which includes avoiding allergens, drug therapy, immunotherapy, and patient education (7). Although drug therapy can control allergic symptoms, it cannot affect the natural process of allergic diseases. Currently, AIT is considered 
Table 8 Comparison of scores between the asthmatic rhinitis group and the asthma-alone group

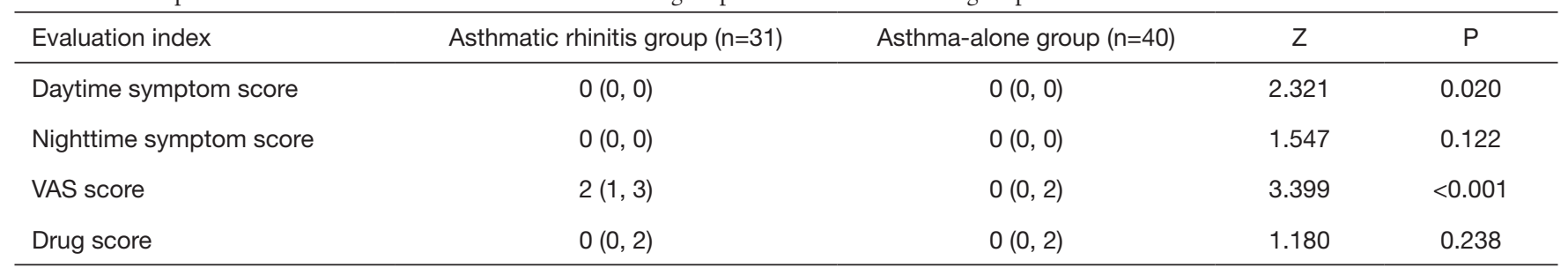

The data were shown as VAS score of asthmatic rhinitis group was higher than that of asthma-alone group, and the difference was statistically significant. There was no significant difference in other scores between the two groups.

Table 9 Comparison of lung function indexes and FeNO levels between the asthmatic rhinitis group and the asthma-alone group

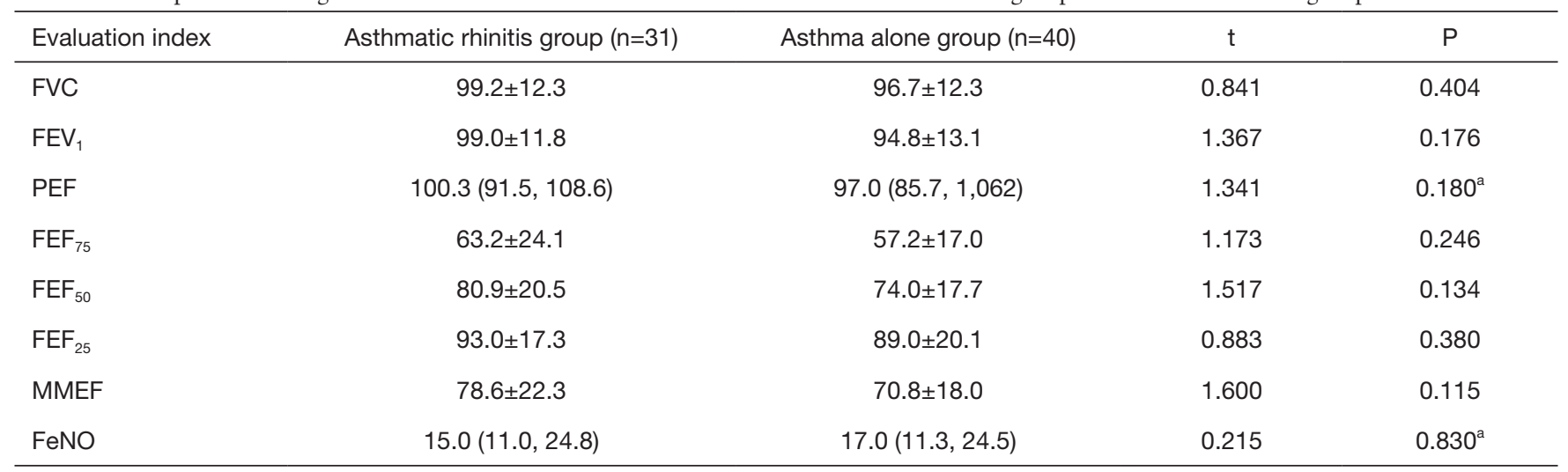

${ }^{a}$, rank-sum test of two independent samples (Mann-Whitney $\cup$ Test). The data were shown as there was no significant difference in lung function and FeNO between the two groups.

as the only treatment method that can change the natural process of allergic diseases. In 2013, WAO confirmed SLIT's therapeutic effect on disease and its reliable safety in the World Allergy Organization position paper 2013 update (17). Its adverse reactions were mild and limited, mainly manifested as tongue itching, swelling, pain, ulcer, taste change, ear itching, sore throat, uvula edema and gastrointestinal symptoms, which could be alleviated by themselves or reduced by drug dosage, and soon alleviated after the administration of symptomatic drugs. It also made it clear that SLIT's application does not need to be conditional on drug treatment failure, and SLIT can be applied in the initial clinical stage and early stage of allergic diseases. In the past 20 years, SLIT has been increasingly recognized as a safe and effective treatment for allergic diseases, especially AR and asthma (18). International studies have reported that SLIT can reduce the symptom scores of children with allergic asthma (19), while research in China shows that specific immunotherapy with dust mite drops can significantly improve the clinical symptoms of asthma and significantly reduce FeNO levels (20). The results of one meta-analysis showed that SLIT brought significant relief of symptoms and reduced medication demand in children with AR (21). Another recent metaanalysis found that SLIT applied to allergy to dust mites could significantly improve allergic symptoms, reduce longterm medication, and improve $\mathrm{FEV}_{1}$ (22). Furthermore, a study in Japan showed that sublingual immunotherapy with house dust mites could significantly improve airflow limitation in patients with allergic asthma complicated with rhinitis ( $\mathrm{FEV}_{1}$ was significantly improved), significantly reduce FeNO level, and reduce airway eosinophilic inflammation (23). Another Chinese study retrospectively analyzed the data of 124 children with asthma and rhinitis treated with sublingual dust mite drops for 3 years, showing that this treatment had a significant effect on children with allergic asthma and rhinitis (24).

A domestic study retrospectively analyzed the data of 124 children with asthma and rhinitis. These children were treated with sublingual dust mite drops for 3 years. The results showed that the treatment was effective in children with allergic asthma and rhinitis. This study is based on 
the expert consensus (16) on mite specific immunotherapy for airway allergic diseases in children, using the symptom drug score as the main therapeutic effect evaluation index. The results showed that the symptom drug score in each group decreased significantly after treatment $(\mathrm{P}<0.05)$, which is consistent with the conclusions of domestic and foreign reports. However, in the asthma-alone group of our study, the improvement of nighttime symptoms after SLIT treatment was not significant compared with that before treatment, which was inconsistent with the above conclusions, and larger-sample-size studies are perhaps needed to produce more conclusive results.

In this study, the pulmonary function and exhaled nitric oxide of the children showed significant improvement in both asthma group and asthmatic group with rhinitis compared with those before treatment. In addition, the present study found that after SLIT treatment, the small airway parameters of lung function $\left(\mathrm{FEF}_{25-75}, \mathrm{FEF}_{75} / \mathrm{FEF}_{25}\right)$ in the two groups were significantly improved compared with those before treatment. Thus far, few studies have been conducted on the effect of SLIT on FeNO level and lung function in children with asthma and rhinitis, especially using the indexes of small airway ventilation. Huang et al. (25) found no significant improvement in lung function after SLIT treatment and a follow-up of 3 years in 26 children with asthma complicated with rhinitis. However, Ma et al. (26) found significant improvement in FEF $25-75 \%$ in 32 asthmatic children after SLIT treatment, but no significant difference in FEV1. Another study by Li et al. (27) showed that SLIT treatment could significantly improve the symptoms of children with asthma complicated with rhinitis, reduce FeNO level, reduce airway inflammation, and improve the ventilation indexes of large and small airway lung function, which was consistent with our study. However, related research from outside China does not seem to be available.

Due the reported advantages of SLIT, which include its reliability and practicality, SLIT has been more commonly used in treating allergic respiratory diseases in China in recent years. However, there are still some unresolved issues related to this therapy. The inflammatory reactions of the upper and lower airways are similar and affect each other, so allergic asthma and rhinitis are described as "the same airway, the same disease" (28), with AR often inducing the attack and deterioration of asthma (29). Our study also found that the VAS score of patients with asthma combined with rhinitis was higher than that of those with asthma alone, which may be related to this phenomenon.
Thus far, few studies have compared the effectiveness of SLIT therapy in children with allergic asthma combined with rhinitis to those with allergic asthma alone. The only relevant Chinese study by $\mathrm{Li}$ et al. (27) showed that SLIT treatment also improved the small pulmonary function airway index, $\mathrm{FEF}_{25}$, in children with asthma at 3, 6, 9, and 12 months compared with treatment in children with asthma combined with rhinitis in the same period; however, other pulmonary function ventilation indexes showed no significant differences. In this study, SLIT significantly improved the clinical symptoms, drug scores, lung function, and FeNO in children with asthma and rhinitis. This could be a result of the children's mild illness and tendency of the disease to be in remission before immunotherapy, and thus our results require confirmation by a larger-sample-size study in the future.

\section{Acknowledgments}

Funding: Health and Family Planning research project in Sichuan Province.

\section{Footnote}

Reporting Checklist: The authors have completed the STROBE reporting checklist. Available at http://dx.doi. org/10.21037/tp-20-322

Data Sharing Statement: Available at http://dx.doi. org/10.21037/tp-20-322

Conflicts of Interest: All authors have completed the ICMJE uniform disclosure form (available at http://dx.doi. org/10.21037/tp-20-322). The authors have no conflicts of interest to declare.

Ethical Statement: The authors are accountable for all aspects of the work in ensuring that questions related to the accuracy or integrity of any part of the work are appropriately investigated and resolved. All procedures performed in this study involving human participants were in accordance with the Declaration of Helsinki (as revised in 2013). The study was approved by ethics board of Chengdu Women and Children Center Hospital and informed consent was taken from all the patients.

Open Access Statement: This is an Open Access article distributed in accordance with the Creative Commons 
Attribution-NonCommercial-NoDerivs 4.0 International License (CC BY-NC-ND 4.0), which permits the noncommercial replication and distribution of the article with the strict proviso that no changes or edits are made and the original work is properly cited (including links to both the formal publication through the relevant DOI and the license). See: https://creativecommons.org/licenses/by-nc-nd/4.0/.

\section{References}

1. Li H, Chen S, Cheng L, et al. Chinese guideline on sublingual immunotherapy for allergic rhinitis and asthma. J Thorac Dis 2019;11:4936-50.

2. National Pediatric Asthma Cooperative Group, Institute of Environmental and Health-related Product Safety, Chinese Center for Disease Control and Prevention. Third nationwide survey of childhood asthma in urban areas of China. Zhonghua Er Ke Za Zhi 2013;51:729-35.

3. Zhao J, Bai J, Shen K, et al. A questionnaire survey on allergic diseases in children aged 0-14 years in the central urban areas of Beijing, Chongqing and Guangzhou. Zhonghua Er Ke Za Zhi 2011;49:740-4.

4. Roberts G, Pfaar O, Akdis CA, et al. EAACI guidelines on allergen immunotherapy: allergic rhinoconjunctivitis. Allergy 2018;73:765-98.

5. Wan WJ, Wang W, Cheng L. A meta-analysis of subcutaneous immunotherapy and sublingual immunotherapy for dust mite allergic rhinitis. Journal of Ear, Nose, Throat and Eye of Shandong University 2017;31:103-8.

6. Miao Q, Wang J, Xu W, et al. Comparison of immune response function between subcutaneous immunotherapy and sublingual immunotherapy in children with asthma. Chinese Journal of Contemporary Pediatrics 2015;17:1210-6.

7. Canonica GW, Cox L, Pawankar R, et al. Sublingual immunotherapy: World Allergy Organization position paper 2013 update. World Allergy Organ J 2014;7:6.

8. Wang J, Chang C, Wei M, et al. Efficacy of sublingual dust mite drops in the treatment of allergic rhinitis in children with single or multiple allergens. Journal of Clinical Otolaryngology Head and Neck Surgery 2008;32:1646-50.

9. Tian M, Lu YQ, Wang Y, et al. Long-term efficacy of sublingual immunotherapy with Dermatophagoides Farianae Drops in children with allergic asthma sensitized to dust mites. Zhonghua Er Ke Za Zhi 2013;51:741-4.

10. Lung Function Specialty Group, Chinese Respiratory Medicine Association. Guidelines for lung function tests (Part II) - Spirometer tests. Chinese Journal of Tuberculosis and Respiratory Medicine 2014;37:481-6.

11. Dweik RA, Boggs PB, Erzurum SC, et al. An official ATS clinical practice guideline: interpretation of exhaled nitric oxide levels (FENO) for clinical applications. Am J Respir Crit Care Med 2011;184:602-15.

12. Pfaar O, Demoly P, Gerth van Wijk R, et al. Recommendations for the standardization of clinical outcomes used in allergen immunotherapy trials for allergic rhinoconjunctivitis: an EAACI Position Paper. Allergy 2014;69:854-67.

13. Potter PC. Update on sublingual immunotherapy. Ann Allergy Asthma Immunol 2006;96:S22-25.

14. Xiang L, Zhao J, Bao Y, et al. Expert consensus on acariespecific immunotherapy for airway allergic diseases in children. Chinese Journal of Applied Pediatrics 2015;33:1215-23.

15. Gordon BR. The allergic march: can we prevent allergies and asthma. Otolaryngol Clin North Am 2011;44:765-77.

16. Li J, Sun B, Zhong N, et al. A multicentre study assessing the prevalence of sensitizations in patients with asthma and/or rhinitis in China. Allergy 2009;64:1083-92.

17. Editorial Board of The Chinese Journal of Pediatrics, Pediatrics Branch of the Chinese Medical Association, Expert consensus on the diagnosis and treatment of allergic diseases in children. Chinese Journal of Pediatrics 2019;57:164-70.

18. Chan TF, Ji KM, Yim AK, et al. The draft genome, transcriptome, and microbiome of Dermatophagoides farinae reveal a broad spectrum of dust mite allergens. J Allergy Clin Immunol 2015;135:539-48.

19. Richards JR, Stumpf JL. House dust mite sublingual immunotherapy for pediatric patients with allergic asthma. Ann Pharmacother 2018;52:1019-30.

20. Chen F, Zhan F. Effect and mechanism analysis of specific immunotherapy with dust mite drops on serum $\operatorname{IgE}$, $\mathrm{FeNO}$ and eosinophils in asthmatic children. Journal of Clinical and Experimental Medicine 2018;12:1320-3.

21. Feng B, Wu J, Chen B, et al. Efficacy and safety of sublingual immunotherapy for allergic rhinitis in pediatric patients: a meta-analysis of randomized controlled trials. Am J Rhinol Allergy 2017;31:27-35.

22. Lin SY, Azar A, Suarez-Cuervo C, et al. Role of sublingual immunotherapy in the treatment of asthma: an updated systematic review. Int Forum Allergy Rhinol 2018;8:982-92.

23. Hoshino M, Akitsu K, Kubota K. Effect of sublingual immunotherapy on airway inflammation and airway wall thickness in allergic asthma. J Allergy Clin Immunol Pract 
2019;7:2804-11.

24. Xing Q, Chen S, Chen B, et al. Efficacy evaluation of sublingual duster mite drops in the treatment of single and multiple allergic rhinitis semi asthma in children. Journal of Clinical Otolaryngology Head and Neck Surgery 2017;31:204-8.

25. Huang H, Liu X, Hou X, et al. The clinical efficacy and airway hyperresponsiveness of dust mite allergen immunotherapy combined with drug therapy in children with asthma with allergic rhinitis. Journal of Capital University of Medical Science 2016;37:568-73.

26. Ma XP, Muzhapaer D. Efficacy of sublingual

Cite this article as: Ai T, Wang L, Luo R, Fan Y, Liao H, Xia W, Zhang L, Duan Y. Effects of sublingual-specific immunotherapy on pulmonary function and exhaled nitric oxide levels in asthmatic children with and without allergic rhinitis. Transl Pediatr 2020;9(5):686-694. doi: 10.21037/tp-20-322 immunotherapy in children with dust mite allergic asthma. Zhongguo Dang Dai Er Ke Za Zhi 2010;12:344-7.

27. Li X. SLIT In the treatment of asthma and Allergic rhinitis in children. Guizhou Medical University, 2019:1-50.

28. Chinese Allergic Rhinitis Research Collaboration group. Expert consensus on subcutaneous immunotherapy for allergic rhinitis 2015. Chinese Journal of Otolaryngology Head and Neck Surgery 2015;22:379-404.

29. Li J, Wang HY, Zhang CQ, et al. Link between allergic rhinitis and asthma. Chin Med J 2006;119:676-83.

(English Language Editor: J. Gray) 